\title{
COVID-19 NO AMAZONAS E A VULNERABILIDADE DA SAÚDE E DA EDUCAÇÃO INDÍGENA
}

\author{
Artemis de Araújo Soares ${ }^{47}$
}

\section{Resumo}

Este artigo vai tratar sobre a pandemia do novo Coronavírus (Covid-19), abordando algumas consequências para os povos indígenas do Amazonas. É importante destacar que a própria Secretaria Especial de Saúde Indígena (Sesai) reconhece que as populações nativas brasileiras são mais vulneráveis às viroses, especificamente as infecções respiratórias como a Covid-19, ocasionando principalmente na morte de crianças e idosos. Apontado pelo Instituto Brasileiro de Geografia e Estatística (IBGE) como o município com maior número de indígenas do País, São Gabriel da Cachoeira, no Noroeste do Amazonas, registrou um rápido avanço da doença entre os povos, além disso, é a cidade com o maior número de contaminação entre índios no Estado: são 3.018 casos e 51 mortes, até dia 25 de agosto de 2020, cujos indígenas eram das etnias: Baré, Baniwa, Tukano, Wanano, Piratapuia, Tariano e Dessano. Em todo o Amazonas dados da primeira semana de outubro de 2020, revelam que o número de casos passa de 144 mil, com mais de 4,2 mil mortes. Deste total, há 836 mortes de indígenas no Brasil, onde 182 são do Amazonas, conforme dados da Articulação dos Povos Indígenas do Brasil (Apib) e Coordenação das Organizações Indígenas da Amazônia (Coiab). Diante deste cenário, o isolamento social altera o cotidiano das famílias, impacta a renda e também compromete a educação nas escolas fechadas em função da crise sanitária.

Palavras-Chave: Povos Indígenas. Coronavírus. Saúde Indígena. Educação Indígena.

\section{Covid-19 in Amazonas and vulnerability in health and indigenous education}

\section{Abstract}

This article will deal with the pandemic of the new Coronavirus (Covid-19), as consequences for the indigenous peoples of Amazonas. It is important to highlight that the Special Secretariat for Indigenous Health (Sesai) recognizes that indigenous peoples are more vulnerable to viruses, specifically respiratory infections such as Covid-19, causing mainly the death of children and the elderly. Named by the Brazilian Institute of Geography and Statistics (IBGE) as the municipality with the most indigenous people in the country, São Gabriel da Cachoeira, in the northwest of Amazonas, recorded a rapid advance of the disease among peoples, in addition, it is the city with the largest number of contamination among Indians in the State: there are 3,018 cases and 51 deaths, until August 25, 2020, whose indigenous people were of the following ethnic groups: Baré, Baniwa, Tukano, Wanano, Piratapuia, Tariano and Dessano. Across the Amazon, data from the first week of October 2020 reveal that the number of cases exceeds 144,000, with more than 4,200 deaths. Of this total, there are 836 deaths of indigenous people in Brazil, of which 182 are from Amazonas, according to data from the Articulation of Indigenous Peoples of Brazil (Apib) and Coordination of Indigenous Organizations in the Amazon (Coiab). Given this scenario, social

${ }^{47}$ Professora Titular da Faculdade de Educação Física e Fisioterapia da Universidade Federal do Amazonas (FEFF/UFAM) e do Programa de Pós-graduação em Sociedade e Cultura na Amazônia - (PPGSCA/UFAM). email: artemissoares@yahoo.com.br 
isolation alters the daily lives of families, impacts income and also compromises education in closed schools due to the health crisis.

Keywords: Indigenous Peoples. Coronavirus. Indigenous Health. Indigenous Education.

\section{Covid-19 en Amazonas y vulnerabilidad en salud y educación indígena}

\section{Resumen}

Este artículo abordará la pandemia del nuevo Coronavirus (Covid-19), como consecuencias para los pueblos indígenas de Amazonas. Es importante resaltar que la Secretaría Especial de Salud Indígena (Sesai) reconoce que los pueblos indígenas son más vulnerables a los virus, especificamente infecciones respiratorias como el Covid-19, causando principalmente la muerte de niños y ancianos. Nombrado por el Instituto Brasileño de Geografía y Estadística (IBGE) como el municipio con más población indígena del país, São Gabriel da Cachoeira, en el noroeste de Amazonas, registró un rápido avance de la enfermedad entre los pueblos, además, es la ciudad con mayor número de contaminación entre indígenas en el Estado: hay 3.018 casos y 51 muertes, hasta el 25 de agosto de 2020, cuyos indígenas pertenecian a las siguientes etnias: Baré, Baniwa, Tukano, Wanano, Piratapuia, Tariano y Dessano. En toda la Amazonía, los datos de la primera semana de octubre de 2020 revelan que el número de casos supera los 144.000, con más de 4.200 muertes. De este total, hay 836 muertes de indígenas en Brasil, de las cuales 182 son de Amazonas, según datos de la Articulación de Pueblos Indígenas de Brasil (Apib) y Coordinación de Organizaciones Indígenas de la Amazonía (Coiab). Ante este escenario, el aislamiento social altera el día a día de las familias, impacta los ingresos y además compromete la educación en escuelas cerradas por la crisis de salud.

Palabras - Clave: Pueblos Indígenas. Coronavirus. Salud indígena. Educación indígena.

\section{Introdução}

A situação da saúde dos povos indígenas no Brasil que já era frágil, ficou bem mais com a pandemia do novo Coronavírus (Covid-19). A etnia dos Kokamas no Amazonas é a mais afetada, segundo a Coordenação das Organizações Indígenas da Amazônia (Coiab), com 57 falecimentos até o dia 05 de outubro de 2020 e no Brasil é a Xavante no Mato Grosso, com 76 mortes no mesmo período. As doenças respiratórias são as principais causas de óbitos entre as populações nativas brasileiras, o que torna a pandemia mais perigosa para idosos e crianças que se encontram em período escolar e estão na fase de desenvolvimento corporal.

De acordo como o Boletim Epidemiológico da Secretaria Especial de Saúde Indígena (Sesai) vinculada ao Distrito Sanitário Especial Indígena (DSEI), até o dia 06 de outubro de 2020, houve 451 óbitos de indígenas no País. Os casos confirmados de Covid-19 contabilizavam 29.132, constatados por teste positivo através da confirmação laboratorial ou confirmados por critérios clínico, clínico-epidemiológico, e clínico-imagem.

Já os recuperados totalizam 24.484, e são os casos que passaram por dez dias em isolamento domiciliar, a contar da data de início dos sintomas, e que estiveram 24 horas assintomáticas. Levantamento da APIB no mesmo período, também afirma que $51 \%$ dos povos indígenas do Brasil já foram afetados pela pandemia de coronavírus. 
No médio Rio Solimões e afluentes houve até o dia 06 de outubro de 2020: 01 caso suspeito, 411 confirmados, 273 descartados, 07 infectados, 393 com cura clínica e 9 óbitos. No alto Rio Juruá houve até o dia 06 de outubro de 2020: 02 casos suspeitos, 741 confirmados, 156 descartados, 117 infectados, 614 com cura clínica e 10 óbitos.

No alto Rio Negro houve até o dia 06 de outubro de 2020: 35 casos suspeitos, 1.738 confirmados, 759 descartados, 401 infectados, 1.322 com cura clínica e 13 óbitos. No alto Rio Purus houve até o dia 06 de outubro de 2020: nenhum caso suspeito,531 confirmados, 289 descartados, 32 infectados, 493 com cura clínica e 05 óbitos.

No alto Rio Solimões houve até o dia 06 de outubro de 2020: 02 casos suspeitos, 1.772 confirmados, 723 descartados, 52 infectados, 1.682 com cura clínica e 35 óbitos. Nesta região há 235 aldeias, desafios antigos da saúde da população indígena se intensificam com a chegada do novo Coronavírus nas aldeias. Em Tabatinga o DSEI é mais afastado, para chegar lá precisa ir de barco ou avião, que dificulta mais o atendimento médico e envio de medicamentos.

A região de fronteira do Alto Solimões, que é próxima da Colômbia, só conta com um hospital e uma Unidade de Pronto Atendimento (UPA) que estavam sobrecarregados. Em cada aldeia o momento é de preocupação e medo, pois as epidemias dizimaram os povos indígenas ao longo da história.

\section{Condições de saúde dos povos indígenas}

No dia 08 de julho, o Sr. Jair Bolsonaro, Presidente do Brasil, sancionou com vetos, a Lei $\mathrm{n}^{\mathrm{o}} 14.021$, de 7 de julho de 2020, com medidas de proteção a povos indígenas durante a pandemia do Coronavírus. O texto, publicado no Diário Oficial da União (DOU), determina que os povos indígenas, as comunidades quilombolas e demais povos tradicionais sejam considerados "grupos em situação de extrema vulnerabilidade" e, por isso, de alto risco para emergências de saúde pública.

Entre os trechos vetados estão os que preveem obrigação do governo em fornecer água potável, higiene, leitos hospitalares e facilidades ao acesso ao auxílio emergencial. Diante desta situação, embora tenham ocorrido avanços nos direitos dos povos indígenas, as condições de saúde vividas por eles ainda são bastante precárias no Estado do Amazonas, região Norte do País.

O descaso vai desde a falta de saneamento básico, segurança alimentar e dificuldades logísticas de socorro às populações isoladas, além de outros. As crianças e idosos se tornam mais vulneráveis às doenças, devido em muitas ocasiões à imunidade baixa.

Deste modo, a pesquisadora, Raquel Raichelis (2000) considera o controle social como um dos elementos constitutivos da estratégia política da esfera pública.

[...] implica o acesso aos processos que informam decisões da sociedade política que devem viabilizar a participação da sociedade civil organizada na formulação e na revisão das regras que conduzem as negociações e arbitragens sobre os interesses em jogo, além da fiscalização daquelas decisões, segundo critérios pactuados. (RAICHELIS, 2000, p.9). 
A população indígena não conta com políticas públicas de saúde adequadas. Muitos adoecem e morrem sem haver diagnóstico adequado da doença, as crianças devido à falta de uma alimentação adequada ficam desnutridas e isso gera mais risco para a infecção do Covid19. Logo, esta proposta pretende reivindicar ao governo brasileiro, de fato cumpra o seu papel.

O Amazonas foi o primeiro Estado a ter a confirmação de indígenas contaminados e hoje concentra o maior número de mortes entre indígenas, chegando a 183 , conforme dados do Comitê Nacional de Vida e Memória Indígena. Vale ressaltar que o Vale do Javarí é um dos principais vetores de expansão da doença dentro dos territórios indígenas, de acordo com a SESAI.

\section{Política de saúde indígena}

De acordo com o Centro Cultural do Ministério da Saúde (CCMS), o marco de início da atual política de saúde indígena pode ser identificado na $1^{\mathrm{a}}$ Conferência Nacional de Proteção à Saúde do Índio foi realizada em novembro de 1986, oito meses após a realização da $8^{\circ}$ Conferência Nacional de Saúde. Teve como temas principais: a criação de um único órgão, vinculado ao ministério responsável pela coordenação do Sistema Único de Saúde (SUS), para gerenciamento da saúde indígena e participação dos indígenas na formulação da política de saúde.

Foi nessa Conferência que ocorreram as primeiras discussões em torno do modelo de atenção à saúde do índio, com a participação de representantes de várias nações indígenas, órgãos públicos e organizações da sociedade civil que atuavam em apoio à causa indígena. Haja vista que foi somente com a Lei Arouca ${ }^{48}$ - Lei n ${ }^{0} 9836$ de 23 de setembro de $1999^{49}$, que foi acrescentado dispositivos à Lei no 8.080, de 19 de setembro de 1990, que "dispõe sobre as condições para a promoção, proteção e recuperação da saúde, a organização e o funcionamento dos serviços correspondentes e dá outras providências". Conforme os artigos a seguir:

Art. 19-A. As ações e serviços de saúde voltados para o atendimento das populações indígenas, em todo o território nacional, coletiva ou individualmente, obedecerão ao disposto nesta Lei.

Art. 19-B. É instituído um Subsistema de Atenção à Saúde Indígena, componente do Sistema Único de Saúde - SUS, criado e definido por esta Lei, e pela Lei no 8.142, de 28 de dezembro de 1990, com o qual funcionará em perfeita integração.

Art. 19-C. Caberá à União, com seus recursos próprios, financiar o Subsistema de Atenção à Saúde Indígena.

Art. 19-D. O SUS promoverá a articulação do Subsistema instituído por esta Lei com os órgãos responsáveis pela Política Indígena do País.

Art. 19-E. Os Estados, Municípios, outras instituições governamentais e nãogovernamentais poderão atuar complementarmente no custeio e execução das ações.

48 Também conhecida como Lei Arouca, devido à atuação do Deputado Sérgio Arouca na sua aprovação.

49 BRASIL. LEI No 9.836, DE 23 DE SETEMBRO DE 1999. Disponível em:<http://www.planalto.gov.br/ccivil_03/leis/19836.htm> Acesso em 06 out. 2020. 
Art. 19-F. Dever-se-á obrigatoriamente levar em consideração a realidade local e as especificidades da cultura dos povos indígenas e o modelo a ser adotado para a atenção à saúde indígena, que se deve pautar por uma abordagem diferenciada e global, contemplando os aspectos de assistência à saúde, saneamento básico, nutrição, habitação, meio ambiente, demarcação de terras, educação sanitária e integração institucional.

Art. 19-G. O Subsistema de Atenção à Saúde Indígena deverá ser, como o SUS, descentralizado, hierarquizado e regionalizado.

$\S 1^{\circ}$. O Subsistema de que trata o caput deste artigo terá como base os Distritos Sanitários Especiais Indígenas.

$\S 2^{\circ}$. O SUS servirá de retaguarda e referência ao Subsistema de Atenção à Saúde Indígena, devendo, para isso, ocorrer adaptações na estrutura e organização do SUS nas regiões onde residem as populações indígenas, para propiciar essa integração e o atendimento necessário em todos os níveis, sem discriminações.

$\S 3^{\circ}$. As populações indígenas devem ter acesso garantido ao SUS, em âmbito local, regional e de centros especializados, de acordo com suas necessidades, compreendendo a atenção primária, secundária e terciária à saúde.

Art. 19-H. As populações indígenas terão direito a participar dos organismos colegiados de formulação, acompanhamento e avaliação das políticas de saúde, tais como o Conselho Nacional de Saúde e os Conselhos Estaduais e Municipais de Saúde, quando for o caso."

Art. 20 O Poder Executivo regulamentará esta Lei no prazo de noventa dias.

Deste modo, é instituído o Subsistema de Atenção à Saúde Indígena, ou seja, é instituído instituiu o subsistema de saúde indígena (SasiSUS), definindo que a organização da atenção à saúde se daria por redes territorializadas de saúde, na forma de 34 Distritos Sanitários Especiais Indígenas de Saúde (DSEI), localizados em diversas regiões do território nacional (Tabela 1):

Tabela 1 - 34 DSEI do território brasileiro

\begin{tabular}{|c|c|c|}
\hline ESTADO & QUANTIDADE & DSEI \\
\hline ACRE & 02 & $\begin{array}{ll}\text { - } & \text { DSEI ALTO PURUS } \\
\text { - } & \text { DSEI ALTO JURUÁ }\end{array}$ \\
\hline ALAGOAS & 01 & - DSEI ALAGOAS \\
\hline AMAZONAS & 07 & $\begin{array}{ll}\text { - } & \text { DSEI ALTO RIO NEGRO } \\
\text { - } & \text { DSEI ALTO SOLIMÕES } \\
\text { - } & \text { DSEI JAVARI } \\
\text { - } & \text { DSEI MANAUS } \\
\text { - } & \text { DSEI MÉDIO PURUS } \\
\text { - } & \text { DSEI PARINTINS } \\
\text { - } & \text { DSEI MÉDIO SOLIMÕES E } \\
& \text { AFLUENTES/ AM/ TEFÉ }\end{array}$ \\
\hline AMAPÁ & 01 & - DSEI AMAPÁ \\
\hline BAHIA & 01 & - DSEI BAHIA \\
\hline CEARÁ & 01 & - DSEI CEARÁ \\
\hline MARANHÃO & 01 & - $\quad$ DSEI MARANHÃO \\
\hline \multicolumn{3}{|c|}{$\sim 47 \sim$} \\
\hline
\end{tabular}




\begin{tabular}{|c|c|c|}
\hline MARANHÃO & 01 & - DSEI MINAS GERAIS \\
\hline ESPÍRITO SANTO & 01 & - DSEI ESPÍRITO SANTO \\
\hline MATO GROSSO DO SUL & 01 & $\begin{array}{llll}\text { - } & \text { DSEI MATO GROSSO DO } \\
\text { SUL } & & & \\
\end{array}$ \\
\hline MATO GROSSO & 04 & $\begin{array}{ll}\text { - } & \text { DSEI CUIABÁ } \\
\text { - } & \text { DSEI MT- COLIDER } \\
\text { - } & \text { DSEI XINGU } \\
\text { - } & \text { DSEI XAVANTE }\end{array}$ \\
\hline PARÁ & 04 & $\begin{array}{ll}\text { - } & \text { DSEI ALTAMIRA } \\
\text { - } & \text { DSEI GUAMÁ TOCANTINS } \\
\text { - } & \text { DSEI KAYAPÓ - REDENÇÃO } \\
\text { - } & \text { DSEI TAPAJÓS }\end{array}$ \\
\hline PARAÍBA & 01 & - DSEI POTIGUARA \\
\hline PERNAMBUCO & 01 & - DSEI PERNAMBUCO \\
\hline PARANÁ & 01 & - DSEI PARANÁ \\
\hline RONDÔNIA & 02 & $\begin{array}{ll}\text { - } & \text { DSEI PORTO VELHO } \\
\text { - } & \text { DSEI VILHENA }\end{array}$ \\
\hline RORAIMA & 02 & $\begin{array}{ll}\text { - } & \text { DSEI LESTE DE RR } \\
\text { - } & \text { DSEI YANOMAMI }\end{array}$ \\
\hline $\begin{array}{l}\text { SANTA CATARINA/ RIO } \\
\text { GRANDE DO SUL }\end{array}$ & 01 & - DSEI SUL SUDESTE \\
\hline TOCANTINS & 01 & - DSEI TOCANTINS \\
\hline
\end{tabular}

Fonte: Elaborado pela Autora (2020) com informações do DSEI

Os três estados com maior número de DSEI são: o Amazonas com sete DSEI, localizados nos municípios de: São Gabriel Cachoeira, Tabatinga, Atalaia do Norte, Lábrea, Manaus, Parintins e Tefé. O Estado de Mato Grosso, com quatro DSEI, localizados nos municípios de Cuiabá, Colider, Canarana e Barra das Garças. E no Estado do Pará com quatro DSEI, localizados nos municípios de Belém, Altamira, Redenção e Itaituba.

Na obra "Lei Arouca 10 Anos de Saúde Indígena" (2009), diferentemente das Coordenações Regionais (Cores) da Funasa, os Dseis não foram divididos por estados, mas, estrategicamente, por área territorial, tendo como base a ocupação geográfica das comunidades indígenas.

Um exemplo dessa política ocorre em Roraima. Lá, o Dsei Yanomami também cuida dos indígenas dessa etnia que vivem no Amazonas, na divisa entre os dois estados.

\section{Vulnerabilidade na saúde e educação indígena}

Além dos 34 DSEI, existem as unidades como os Postos de Saúde, Polos-Base e as Casas de Apoio à Saúde do Índio (Casais) estão à disposição das comunidades indígenas. Mas além dos cuidados com a saúde, é importante ressaltar que, apenas na década de 1990, o índio brasileiro passou a ser inserido na educação superior. Eles ainda lutam pelos seus direitos junto ao Ministério da Educação (MEC), Fundação Nacional do Índio (FUNAI), entre outras entidades.

Nesta proposta, além de ser descrita a vulnerabilidade da saúde da criança indígena, vai ser analisado como esta pandemia do Covid-19 afetou também a escolaridade, uma vez 
que a evolução da educação indígena tem como marco a Constituição Federal Brasileira de 1988.

Na contemporaneidade, o índio é visto como uma atração turística para quem visita a Amazônia. Essa ideia precisa ser deixada de lado, uma vez que eles representam as primeiras civilizações locais. Logo, sua cultura, tradições e costumes devem ser valorizados a partir do respeito. A partir do momento em que não se queira modificar seus hábitos nem sua cosmologia, e se um ensino fundamental, médio ou superior for dado pelas escolas e universidades tradicionais, estes devem promover um ensino bilíngue, para que se preserve a língua nativa.

Por conseguinte, ao pensar em uma educação do índio, é necessário criar uma metodologia de ensino específica, na qual se leve em consideração os elementos desses povos e durante a pandemia do Covid-19, muitas comunidades foram afetadas em relação ao ensino escolar das crianças.

Na capital do Estado do Amazonas, Manaus, há quatro escolas de Ensino fundamental, que funcionam em comunidades indígenas e para preservar a cultura dos povos tradicionais, foi estabelecido pelo Prefeito Arthur Neto, o Decreto Municipal 1.394/2014, que assegura aos indígenas a prerrogativa de definir as nomenclaturas das escolas situadas em comunidades tradicionais. A alteração dos nomes das escolas foi publicada no Diário Oficial do Município de Manaus (DOM), na edição 3.456, de 23 de julho de 2014.

A decisão foi tomada após várias reuniões com as diversas comunidades e a mudança tem o intuito de preservar a cultura indígena. O Decreto 1.394, Artigo 2, diz que "a escola indígena adotará o nome a partir da definição do povo ou da comunidade a que se destinar".

Mudaram de nome as escolas municipais São Thomé, na comunidade de Paraná do Samaúma, que passa a se chamar Escola Indígena Municipal Kunya Taputira; Aleixo Bruno, na comunidade Terra Preta, que passa a se chamar Escola Indígena Municipal Yayumbwewa Rendawa Maku Arú Waimi; Três Unidos, na comunidade Três Unidos-Rio Cuieira, que passa a se chamar Escola Indígena Municipal Kanata T-Ykua; e Boas Novas, na comunidade Viva Nova Esperança, que passa a se chamar Escola Indígena Municipal Puranga Pisasú. (SEMED, 2014).

As escolas, com a nova denominação, de acordo com o projeto de Lei, estão incluídas na estrutura básica da Secretaria Municipal de Educação (Semed) em Manaus. Em 2012, o Ministério da Educação (MEC) realizou o Censo Escolar de Educação Básica, onde se dá um panorama da Educação Indígena no Brasil. O crescimento do número de escolas com educação indígena, nos últimos quatro anos, vem se estabilizando.

Entre os anos de 2009 a 2012, o crescimento do número de escolas foi de apenas $9,7 \%$. A região Sudeste ainda apresentou uma queda no número de escolas de $10,2 \%$. A maioria das escolas indígenas se concentra nas redes estaduais e municipais de educação, tendo, respectivamente, $46 \%$ e $52 \%$ do total.

As escolas indígenas localizam-se em áreas rurais, demonstrando a forte ligação da educação indígena com as questões da terra. Ressalta-se que, quando analisamos os dados de localização diferenciada da escola, $92 \%$ das escolas encontram-se em terras indígenas. 
Ainda conforme o Censo de 2012, a propósito da quantidade de docentes em escolas de Educação Indígena no Brasil, por região, de 2009 a 2012, verificou-se que, a partir de 2010, o número de docentes em escolas de educação indígena se manteve estável na faixa de 14.000 docentes.

Conforme o Parecer do Conselho Nacional de Educação CNE/CEB $N^{\circ} 13$, editado no ano de 2012, os Estados devem estruturar, nas secretarias de Educação, instâncias administrativas de Educação Escolar Indígena com a participação de indígenas e de profissionais especializados, destinando-lhes recursos financeiros específicos. Tal medida, contudo, ainda figura apenas no plano legal.

$\mathrm{Na}$ esmagadora maioria dos casos, isso decorre do desrespeito, demonstrado por alguns Estados e municípios, a premissas já consolidadas como a de que as escolas indígenas são unidades próprias, autônomas e específicas, e que podem, portanto, criar projetos pedagógicos próprios, organizar grades curriculares e calendários que considerem as culturas de cada povo ${ }^{50}$.

Vale ressaltar que diante do cenário epidemiológico com o surgimento do Coronavírus, a educação escolar indígena sofreu mudanças, o primeiro caso confirmado de contaminação por Covid-19 entre indígenas brasileiros foi de uma jovem de 20 anos do povo Kokama, no dia 25 de março de 2020, no município amazonense Santo Antônio do Içá (distante a 885.86 quilômetros de Manaus). O contágio foi feito por um médico vindo de São Paulo a serviço da Secretaria Especial de Saúde Indígena (SESAI), que estava infectado com o vírus. Atualmente, os Kokama são os mais afetados em casos de mortes no Amazonas.

Em relação à política de atenção à saúde dos povos indígenas no Brasil, é interessante destacar que foi assinada em março de 2010 a Medida Provisória 483/2010, transferindo a competência da saúde indígena da FUNASA para uma nova Secretaria de Saúde Indígena. Atualmente a Secretaria Especial de Saúde Indígena (SESAI) é responsável por coordenar e executar a Política Nacional de Atenção à Saúde dos Povos Indígenas e todo o processo de gestão do Subsistema de Atenção à Saúde Indígena (SasiSUS) no Sistema Único de Saúde (SUS).

A SESAI é estruturada em: Departamento de Atenção à Saúde Indígena (DASI); Departamento de Determinantes Ambientais Saúde Indígena (DEAMB); Distrito Sanitário Especial Indígena (DSEI) e Coordenação Geral de Planejamento e Orçamento (CGPO). Todas atuam para orientar o desenvolvimento das ações de atenção integral à saúde indígena e de educação em saúde segundo as peculiaridades, o perfil epidemiológico e a condição sanitária de cada Distrito Sanitário Especial Indígena, em consonância com as políticas e os programas do SUS, às práticas de saúde e às medicinas tradicionais indígenas, e a sua integração com as instâncias assistenciais do SUS na região e nos Municípios que compõem cada Distrito Sanitário Especial Indígena.

De acordo com o Plano Distrital de Saúde Indígena (quadriênio 2020 -2023), o Panorama dos Povos Indígenas no Brasil se dá desta forma: São 311 etnias com 760.350 Indígenas, 6.238 aldeias, 34 Distritos Sanitários Especiais Indígenas (DSEI), 67 Casas de Apoio a Saúde Indígena (CASAI), 1.199 Unidades Básicas de Saúde Indígena (UBSI): 1.199.

50 Conferir em: RANGEL, Lúcia Helena Vitalli. Relatório de Pesquisa 2012 - Violência contra os Povos Indígenas no Brasil, 2013. p.108. Disponível em: <http://www.cimi.org.br/pub/viol/viol2012.pdf> Acesso em: 27 jul. 2020. 
Além da população Sateré-Mawé de Manaus (Imagem 1), conforme declara o Conselho Geral da Tribo Sateré-Mawé (CGTSM), também é expressiva a presença desta etnia nas cidades mais próximas da TI Andirá-Marau, nos municípios amazonenses de Barreirinha, Parintins e Maués.

Imagem 1 - população Sateré-Mawé

\begin{tabular}{lc}
\hline Cidade & $N^{0}$ habitante \\
\hline Barreirinha & 276 \\
\hline Parintins & 512 \\
\hline Maués & 200 \\
\hline Manaus & 600
\end{tabular}

Fonte: Conselho Geral da Tribo Sateré-Mawé - CGTSM

Conforme dados do Instituto Brasileiro de Geografia e Estatística (IBGE), referentes ao Censo de 2010, o Brasil possui uma população indígena estimada em 896.917, composta por 305 etnias, falantes de 274 idiomas, espalhados em todas as regiões brasileiras, porém, há uma concentração maior na região Amazônica. Deste total, 517.383 estão vivendo em Terras Indígenas, enquanto 379.534 pessoas vivem fora destas Terras.

No dia 27 de março de 2014, a Lei 12.960/2014, alterou a Lei 9.394, de 20 de dezembro de 1996 - Lei de Diretrizes e Bases da Educação (LDB), que estabelece as diretrizes e bases da educação nacional, para fazer constar a exigência de manifestação de órgão normativo do sistema de ensino para o fechamento de escolas do campo, indígenas e quilombolas.

Art. $1^{\circ} \mathrm{O}$ art. 28 da Lei $\mathrm{n}^{\circ} 9.394$, de 20 de dezembro de 1996, passa a vigorar acrescido do seguinte parágrafo único:

“Art. 28

Parágrafo único. O fechamento de escolas do campo, indígenas e quilombolas será precedido de manifestação do órgão normativo do respectivo sistema de ensino, que considerará a justificativa apresentada pela Secretaria de Educação, a análise do diagnóstico do impacto da ação e a manifestação da comunidade escolar.”.

Art. $2^{\circ}$ Esta Lei entra em vigor na data de sua publicação.

Para que haja um entendimento se faz necessário contextualizar que a partir de 1910, segundo Souza Lima e Barroso-Hoffman (2007), foi criado o Serviço de Proteção aos Índios (SPI), que implantou uma rede de escolas para ensinar- lhes as primeiras letras. A partir de 1967, a Fundação Nacional do Índio (FUNAI) substituiu o SPI, e transformou as escolas das comunidades indígenas em uma rede de escolas bilíngues, com alguns professores índios ministrando aulas da língua e algumas tradições.

No ano de 1988, a Constituição Federal Brasileira assegurou aos povos indígenas alguns direitos fundamentais, especificamente relacionados à educação, como o direito à 
diversidade cultural. No ano de 1991, surgiu o primeiro marco legal, conhecido como Decreto Presidencial no 26/1991, que conferiu ao Ministério da Educação (MEC) a competência para integrar a educação escolar indígena aos sistemas de ensino regular. No mesmo passo, retirouse da FUNAI o encargo de organizar e executar as ações relacionadas à educação no seio das comunidades indígenas.

Em 1993, o MEC produziu o primeiro documento sobre educação escolar indígena, que falava da construção de currículos para a alfabetização e de $1^{a}$ a $4^{a}$ série, além de destacar a formação de professores de nível médio. Em 1994, foi constituída uma coordenação no Ministério da Educação para cuidar da educação indígena; ela recebeu o nome de Coordenação Geral de Apoio às Escolas Indígenas - nome que caracteriza bem qual o trabalho a ser desenvolvido. (SOUZA LIMA; BARROSO-HOFFMANN, 2007, p. 91).

Para dar suporte à educação que ora está em sala de aula, fazendo uso do método tradicional de ensino, o qual, em muitas situações, se faz na própria comunidade indígena ou espaço não-formal -, foi iniciado, em 1995, no Brasil, um projeto de formação de professores falantes da língua indígena, tanto nas etapas presenciais como nas nãopresenciais: era o projeto Yanomami.

Em seguida, surgia a Lei de Diretrizes e Bases da Educação (LDB), Lei N 9.394, de 20 de dezembro de 1996, que abraçou o princípio de que os objetivos, currículos e calendários escolares, nas escolas indígenas, seriam definidos por cada comunidade. No que diz respeito à educação superior, a Lei pontua que deve ser estimulada a criação cultural, o desenvolvimento do espírito científico e o do pensamento reflexivo; além disso, nas suas disposições gerais, ressalta:

Art. 78. O Sistema de Ensino da União, com a colaboração das agências federais de fomento à cultura e de assistência aos índios, desenvolverá programas integrados de ensino e pesquisa, para oferta de educação escolar bilíngue e intercultural aos povos indígenas, com os seguintes objetivos:

I - proporcionar aos índios, suas comunidades e povos, a recuperação de suas memórias históricas; a reafirmação de suas identidades étnicas; a valorização de suas línguas e ciências;

II - garantir aos índios, suas comunidades e povos, o acesso às informações, conhecimentos técnicos e científicos da sociedade nacional e demais sociedades indígenas e não-índias.

Com as discussões e os movimentos indígenas em torno da temática da educação, foi criado, em 1998, o Referencial Curricular Nacional para as Escolas Indígenas. Com este documento e a Resolução no 03/99, da Câmara de Educação Básica do Conselho Nacional de Educação (CEB/CNE), as Diretrizes Curriculares Nacionais da Educação Escolar Indígena 
foram aprovadas, em 14 de setembro de 1999, tendo como fundamento o Parecer no 14/99 do CNE.

Dessa forma, ficou determinado que os professores das escolas indígenas fossem, prioritariamente, membros de suas próprias comunidades, ou seja, índio ensinando índio, através das Políticas Públicas estabelecidas pelo MEC.

Mas diante do cenário do Coronavírus (Covid-19), a orientação é para que indígenas fiquem nas aldeias durante a pandemia, e o período escolar será alterado até que tudo se normalize.

Neste sentido, educação de qualidade aos povos indígenas, principalmente no que diz respeito à formação inicial, bem como ações para que crianças saiam da vulnerabilidade de doenças como o Covid-19, são extremamente necessários para uma qualidade de vida a estes povos que são verdadeiros guerreiros no Brasil.

\title{
CONSIDERAÇÕES
}

Durante a pandemia do Covid-19, verifica-se que a ausência de políticas os povos indígenas em uma dura realidade. No interior do Amazonas há precariedade em um atendimento clínico, Unidades de Terapias Intensivas (UTIs) acabam se tornando inexistentes, onde muitos viajam para a capital Manaus em busca de tratamento. A questão da educação com acesso remoto ainda está longe da realidade das crianças indígenas, neste período onde não há um plano emergencial voltado a esses povos, apesar do Governo Brasileiro dizer que existe.

Apesar dos indígenas estarem, muitas vezes, distantes dos centros urbanos, a aproximação de pessoas de fora como os próprios profissionais de saúde, torna escasso o Equipamento de Proteção Individual (EPI), colocando em risco de contaminação. Assim como saída de indígenas das suas comunidades, para terem acesso ao auxílio emergencial é uma das situações preocupantes, pois uma das principais característica da Amazônia é o isolamento dos municípios, as dificuldades de comunicação, transporte e logística.

Vale enfatizar que os dados de óbitos entre indígenas divergem, como ocorreu no dia 06 de outubro de 2020, onde foi divulgado pela Articulação dos Povos Indígenas do Brasil (Apib) 836 indígenas mortos pela COVID-19, enquanto que pela Secretaria Especial de Saúde Indígena (Sesai) vinculada ao Distrito Sanitário Especial Indígena (DSEI), no mesmo período, houve 451 óbitos de indígenas no País. A diferença se dá porque os DSEI não realizam o registro de contágios de índios que vivem no meio urbano, considerado pelas lideranças indígenas a contagem independente.

\begin{abstract}
Abandonam outros e assim criam e recriam novas formações, denominadas [...] de sociedades translocais, pois as sociedades transculturais têm seu lócus na terra natal e o seu eu e sua forma de vida possuem um caráter especialmente centrado na vida presente (PAIVA e SOARES, 2015, p. 6).
\end{abstract}

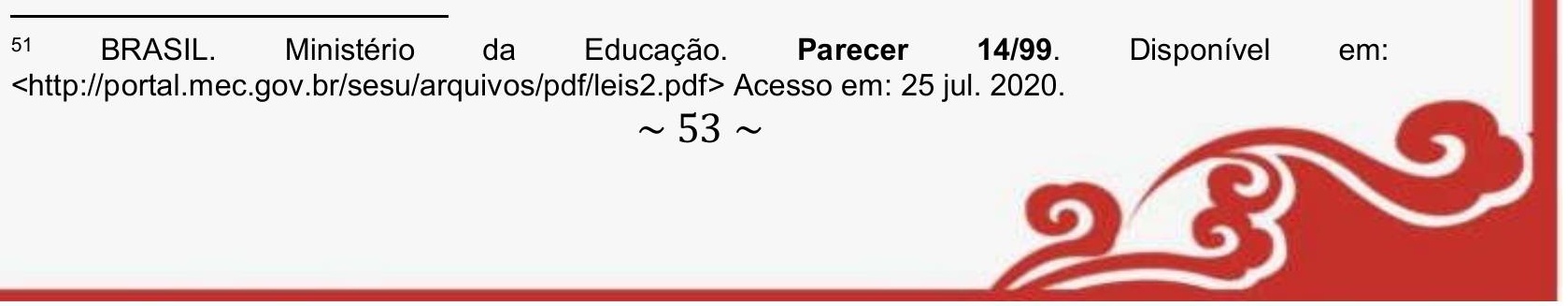


Aqui se observa o processo migratório da aldeia para a cidade, a partir dos referenciais de moradia, trabalho, lazer, saúde e educação. Para Agnes Heller (1972), a vida cotidiana está no centro do acontecer histórico e envolve o homem inteiro, em todos os seus aspectos.

Ao reportar sobre a relação do indígena com o espaço urbano, é importante relacionar que estes locais a partir de sua extensão, são mais complexos e múltiplos, as práticas sociais e os processos de identificação dos grupos sociais são cada vez mais isolados, ocasionando dificuldades de identificação destes índios urbanos, na contabilidade dos casos de suspeita, infecção e mortes pelo Coronavírus (Covid-19). Espera-se que haja o mais rápido possível o enfrentamento do Coronavírus, para que todos possam viver de forma saudável.

\section{REFERÊNCIAS}

BRASIL. Fundação Nacional de Saúde. Lei Arouca 10 Anos de Saúde Indígena. - Brasília: Funasa, 2009. Disponível em:<http://www.funasa.gov.br/site/wp-content/files_mf/livro-leiarouca-10anos.pdf> Acesso em 04 out. 2020.

BRASIL. Sobre a SESAI. Disponível em: $<$ https://www.saude.gov.br/saude-indigena/sobrea-sesai $>$ Acesso em 23 jul.2020.

BRASIL. Lei no 12.960, de 27 de março de 2014. Diário Ofícial da União, Brasília, DF, 28 de março de 2014. Disponível em: http://www.planalto.gov.br/ccivil_03/_Ato20112014/2014/Lei/L12960.htm Acesso em: 26 jul. 2020.

BRASIL. Constituição (1988). Constituição da República Federativa do Brasil. Brasília, DF: Senado Federal: Centro Gráfico, 1988.

BRASIL. Lei $\mathbf{n}^{\mathbf{0}} \mathbf{1 4 . 0 2 1}$, de $\mathbf{7}$ de julho de 2020. Disponível em: $<$ http://www.in.gov.br/en/web/dou/-/lei-n-14.021-de-7-de-julho-de-2020-265632745> Acesso em 27 jul. 2020.

BRASIL. Ministério da Educação. Lei no 9.394, de 20 de dezembro de 1996. Estabelece as diretrizes e bases da educação nacional. Diário Oficial da União. Brasília, DF, 23 dez. 1996. Disponível em: <http://portal.mec.gov.br/arquivos/pdf/ldb.pdf> Acesso em: 26 jul. 2020.

FUNAI - Fundação Nacional do Índio. Educação Escolar Indígena. Disponível em: < http://www.funai.gov.br/index.php/educacao-escolar-indigena> Acesso em: 26 jul. 2020.

GENIOLE, Leika Aparecida Ishiyama; .[et al.]. A Saúde da Família Indígena- Campo Grande, MS : Ed. UFMS : Fiocruz Unidade Cerrado Pantanal, 2011.

IBGE. Censo: População em 2010. Instituto Brasileiro de Geografia e Estatística. Disponível em: <http//www.ibge.gov.br/censo2010/dados_divulgados/índex.php?uf=13>. Acesso em: 26 jul. 2020.

Censo Demográfico 2010. Características gerais dos indígenas. Instituto Brasileiro de Geografia e Estatística. Disponível em: $<\mathrm{ftp}: / / \mathrm{ftp}$. ibge.gov.br/Censos/Censo_Demografico_2010/Caracteristicas_Gerais_dos_Indigen as/pdf/Publicacao_completa.pdf $>$ Acesso em: 26 jul. 2020. 
MANAUS. Diário Oficial do Município de Manaus (DOM), 23 jul. 2014 - Edição 3.456. Disponível

em: $<$ http://dom.manaus.am.gov.br/pdf/2014/julho/DOM\%203456\%2023.07.2014\%20CAD\% 201.pdf/view> Acesso em: 26 jul. 2020.

PAIVA, Ignês Tereza Peixoto de; SOARES, Artemis. O cotidiano de indígenas urbanos no baixo amazonas, Amazônia brasileira. III Congresso Pan-Amazônico de História Oral. IX Encontro Regional do Norte de História Oral. VIII Semana de História do Cesp - UEA (2015). Disponível

em: $<$ https://www.norte2015.historiaoral.org.br/resources/anais/12/1444082900_ARQUIVO_Arti goIgnesTerezaPeixotodePaiva.pdf>. Acesso em 02 Out. 2020.

RAICHELIS, R. Esfera pública e os conselhos de assistência social: caminhos da construção democrática. São Paulo: Cortez, 1998. 